\title{
BIOÉTICA E ATENÇÃO BÁSICA: UM ESTUDO EXPLORATÓRIO DOS PROBLEMAS ÉTICOS VIVIDOS POR ENFERMEIROS E MÉDICOS NO PSF*
}

[Bioethics and primary care: an exploratory study of ethical problems experienced by nurses and physicians at the F amily Health Program (FHP)]

[Bioética y cuidados primarios: una investigación exploratoria de los problemas eticos vividos por enfermeros y medicos del PSF ]

\author{
Luana Torelli da Silva**, Elma L ourdes Campos Pavone Zoboli***, A na L uiza Vilela B orges****
}

RESUMO: Estudo quantitativo exploratório para identificar e verificar a freqüência dos problemas éticos vividos por enfermeiros e médicos no PSF. Coleta de dados com questionário auto-aplicado, contendo situações geradoras de problemas éticos e escala de quatro pontos para a freqüência. Desrespeito do profissional para com o usuário; problemas relacionados às informações para usuários e famílias eà preservação da privacidade e confidencial idade apareceram na mai oria dos questionários, embora com freqüências diferentes. Os resultados indicam que a bioética na atenção básica lida com situações do cotidiano e não com dilemas de maior apelo dramático. A sutileza desse panorama pode levar a não percepção dos problemas, reforçando a necessidade de capacitação dos profissionais em comunicação e acol himento, para instituir uma atitude ética baseada na cidadania, solidariedade e humanismo.

PALAVRAS-CHAVE: B ioética; A tenção primária à saúde; Programa Saúde da Família; Humanização da assistência.

ABSTRACT: Quantitative exploratory study on ethical problems in primary care. The objectives were to identify and check the frequency of ethical problems experienced by nurses and physicians at the Family Health Program. Data collection used a self- applied questionnaire with ethical problems' generating situations and a four-point scale for occurrence frequency. Professional disrespect to the patient, problems concerning information to patients and families and those related to privacy and confidentiality appeared in all questionnaires, in different degrees. R esults show that ethical problems in primary care deal with typical situations in daily care and not dramatic ones. This reinforces the core role of communication and healing skills in primary care professional practice to foster an ethical attitude based on citizenship, solidarity and humanity.

KEYWORDS: B ioethics; Primary health care; Family Health Program; Humanization of assistance.

RESUMEN: Investigación cuantitativa, exploratoria para identificar y verificar la frecuencia de problemas éticos vividos en el Programa Salud de la Familia. Para recoger los datos se utilizó cuestionario autoaplicado, con situaciones generadoras de problemas éticos y escal a de cuatro puntos para frecuencia. Trato irrespetuoso del usuario; problemas rel acionados a información para usuarios y familias, preservación de privacidad y confidencialidad aparecieron en la mayoría de los cuestionarios, sin embargo con frecuencias distintas. L os resultados plantean para la bioética en atención básica situaciones cotidianas y no dilemas de gran apelo dramático. Esto puede resultar en la no percepción de los problemas. Hace falta capacitar los profesionales para comunicación y acogimiento con vistas a instituir una actitud ética basada en ciudadanía, solidariedad y humanismo.

PALABRAS CLAVE: Bioética; A tención primaria de salud; Programa Salud de la Familia; Humanización de la atención.

\footnotetext{
* Projeto financiado com bolsa de iniciação científica da Fundação de A mparo à Pesquisa de São Paulo - FA PESP.

**M estranda do Programa de Pós Graduação em Enfermagem da Escola de Enfermagem da Universidade de São Paulo - USP.

***Professora doutora do Departamento de Enfermagem em Saúde Coletiva da Escola de Enfermagem da USP.

***** Professora doutora do Departamento de Enfermagem em Saúde Coletiva da Escola de Enfermagem da USP.
} 


\section{INTRODUÇÃO}

A atenção à saúde realizada nas unidades de saúde merece lugar na agenda bioética. Os problemas do cotidiano perdem espaço para as "situações limite", que sendo dramáticas e requererem soluções imediatas são mais estudadas. A desconsideração das situações cotidianas confereincompletude à abrangência da bioética, pois foca problemas éticos de centros especializados, esquecendo que a atenção à saúde não é um conjunto homogêneo de serviços e ações. Os problemas de saúde diferem quanto ao nível das ações e procedimentos oferecidos pelos serviços, assim como os usuários, os familiares e os profissionais de saúde, além dos cenários das instituições quetambém são diferentes, sem mencionar as distintas sol uções possíveis paraum mesmo problema. Isto indica que as situações da atenção básica trazem problemas éticos distintos dos vividos na atenção terciária ${ }^{(1,2,3,4) \text {. }}$

Pesquisa com enfermeiros e médicos do Programa Saúde da Família (PSF) no município de São Paulo mostra estas diferenças, a começar pela sutileza e escopo dos problemas éticos vividos na atenção básica, que são, em geral, preocupações do cotidiano da atenção à saúde e não "situações limite", críticas, dramáticas ou dilemáticas. Entretanto, isto não significa que estes problemas sejam menos importantes, mas que a atenção básica lida com fatos e valores distintos, a sua maneira, amplos e complexos, embora de menor apelo dramático ${ }^{(5)}$.

Os encontros com os usuários na atenção básica caracterizam-se por episódios repetidos e aparentemente simples, diferentes das crises bem definidas que pedem prontas soluções, típicas da atenção terciária. Por isso, o modo como os problemas éticos emergem na atenção básica pode dificultar o seu discernimento ${ }^{6}$. Porém, a fal ha em perceber os problemas éticos vividos na atenção primária pode por em risco a atenção à saúde prestada nas unidades básicas, rompendo o vínculo estabelecido entre os profissionais e os usuários, pois mesmo que os problemas sejam sutis a ponto de passarem despercebidos, se manejados inadequadamente, podem trazer consequiências desastrosas para os usuários individualmente, para as famílias, para as relações destes com a equipe de saúde e para a comunidade adscrita ${ }^{(5)}$.

Tais preocupações motivaram o presente estudo que visou contribuir para o delineamento da interface entre a bioética e a atenção básica, com os objetivos de: identificar os problemas éticos vivenciados por enfermeiros e médicos que atuam no PSF e verificar a freqüência com que estes profissionais se deparam com tais problemas éticos.

\section{PERCURSO METODOLÓGICO}

Esta pesquisa, financiada com bolsa de iniciação científica da Fundação de A mparo à Pesquisa de São Paulo (FAPESP), é quantitativa, exploratória, situada no escopo da ética descritiva, enquanto estudo empírico, de cunho não normativo. A ética descritiva investiga factual mente a conduta moral por meio de procedimentos científicos para estudar as atitudes das pessoas (77,99). 0 estudo empírico, de cunho não normativo identifica e caracteriza problemas éticos surgidos na prática da atenção à saúde, contribuindo para uma bioética voltada aos problemas reais ${ }^{(10)}$.

0 cenário foi em unidades básicas de saúde, no município de São Paulo, que contavam com o PSF. Foram incluídos 24 enfermeiros e 22 médicos, totalizando 46 sujeitos, distribuídos pelas diversas regiões da cidade. As unidades básicas foram selecionadas por sorteio e os profissionais por convite.

Dos 24 enfermeiros, três $(12,5 \%)$ eram do sexo masculino. A média de idade, excluído um sem resposta, foi de 35 anos, com extremos de 24 e 50.0 tempo médio de trabal ho como enfermeiro era de, aproximadamente, 11 anos eno PSF em torno de dois anos emeio. A penas três enfermeiros $(12,5 \%)$ trabal havam no PSF há menos de um ano.

Dos 22 médicos, metade era do sexo masculino. 0 tempo de trabalho como médico era de mais de 13 anos, retirados dois profissionais que trabal havam há menos de um ano. No PSF, o tempo médio de trabalho era de, aproximadamente, três anos, com quatro médicos tendo registrado menos de um ano. A idade média era de 36 anos, com extremos de 24 e 60, excluído um sem resposta.

0 projeto foi aprovado pelo Comitê de Ética em Pesquisa da Prefeitura M unicipal de São Paulo e autorizada realização da pesquisa (SM S 85/2004, junho). A coleta de dados foi feita entre setembro de 2004 a fevereiro de 2005. Para os sujeitos foi pedido o consentimento livree esclarecido. 0 instrumento foi um questionário estruturado, auto-aplicado, construído a partir dos problemas éticos apontados por enfermeiros e médicos de equipes de PSF na pesquisa de Zoboli ${ }^{5}$. Para cada situação listada foram incluídas alternativas com base em uma escala ordinal de quatro pontos, adaptada de Robillard, Sebastian e Perrit (11): "não considero problema ético"; "considero problema ético e nunca encontrei", "considero problema ético e o encontro comumente" e "considero problema ético e o encontro ocasionalmente".

$O$ banco de dados foi feito em WINDOWS EXCEL 98 e analisado com SPSS for Windows 11.0 (Statistical Package for Social Sciences) e EPIINFO 6.0. Os resultados foram apresentados por meio de números absolutos, médias e proporções, comparadas pelo teste de associação Quiquadrado, segundo a categoria profissional (enfermeiros e médicos). $\mathrm{N}$ as variáveis em que houve cinco ou menos observações em al guma categoria utilizou-se o Teste Exato de Fischer.

\section{RESULTADOSE DISCUSSÃO}

Os resultados estão agrupados em três categorias: "problemas éticos nas relações com os usuários e famílias"; "problemas éticos nas relações da equipe" e "problemas éticos nas relações com a organização e o sistema de saúde". 
3.1 PROBLEMAS ÉTICOS NAS RELAÇÕES COM USUÁRIOSE FAMÍLIAS

O PSF propõe a reorganização da atenção básica a partir da família, que passa a ser entendida e percebida em seu ambiente físico e social, permitindo às equipes maior amplitude na compreensão do processo saúde-doença e da necessidade de intervenções além das práticas curativas. Daí decorre a importância da qualidade da relação mantida entre a equipe, os usuários e as famílias. $\mathrm{Na}$ tabela 1 , apresenta-se a distribuição e correlação dos problemas éticos segundo a percepção dos dois grupos profissionais.

Tabela 1 - Distribuição e associação da percepção das situações listadas como problemas éticos nas relações com os usuários e as famílias segundo categoria profissional. São Paulo, 2004-2005

\begin{tabular}{|c|c|c|c|c|c|c|c|}
\hline \multirow{3}{*}{$\begin{array}{l}\text { Situação } \\
\begin{array}{l}\text { 1. Dificuldade em estabelecer os limites da relação } \\
\text { profissional-usuário }\end{array}\end{array}$} & \multirow{2}{*}{$\begin{array}{c}\text { Problema } \\
\text { Sim }\end{array}$} & \multicolumn{2}{|c|}{ Enfermeiros (no- \%) } & \multicolumn{2}{|c|}{ Médicos $\left(n^{0}-\%\right)$} & \multirow{2}{*}{$\begin{array}{c}\text { Total } \\
38\end{array}$} & \multirow{2}{*}{$\frac{\mathbf{p}}{1,0000}$} \\
\hline & & 20 & 83,34 & 18 & 81,82 & & \\
\hline & Não & 4 & 16,66 & 4 & 18,18 & 8 & \\
\hline \multirow{2}{*}{$\begin{array}{l}\text { 2. Pré-julgamento dos usuários dos serviços por parte das } \\
\text { equipes }\end{array}$} & Sim & 21 & 95,84 & 21 & 95,46 & 42 & - \\
\hline & Não & 1 & 4,16 & 1 & 4,54 & 2 & \\
\hline \multirow[t]{2}{*}{ 3. Desrespeito do profissional para com o usuário } & $\operatorname{Sim}$ & 24 & 100,00 & 21 & 100,00 & 45 & - \\
\hline & Não & - & - & - & - & - & \\
\hline \multirow{2}{*}{ 4. Indicações clínicas inadequadas } & $\operatorname{Sim}$ & 21 & 91,67 & 18 & 90,91 & 39 & 1,0000 \\
\hline & Não & 2 & 8,33 & 2 & 9,09 & 4 & \\
\hline \multirow{2}{*}{$\begin{array}{l}\text { 5. Prescrição de medicamentos que o usuário não poderá } \\
\text { comprar }\end{array}$} & $\mathrm{Sim}$ & 19 & 79,17 & 18 & 81,82 & 37 & 1,0000 \\
\hline & Não & 5 & 20,83 & 4 & 18,18 & 9 & \\
\hline \multirow{2}{*}{$\begin{array}{l}\text { 6. Prescrição de medicamentos mais caros com eficácia igual } \\
\text { a dos mais baratos }\end{array}$} & $\operatorname{Sim}$ & 19 & 79,17 & 19 & 86,36 & 38 & 0,7021 \\
\hline & Não & 5 & 20,83 & 3 & 13,63 & 8 & \\
\hline \multirow[t]{2}{*}{ 7. Solicitação de procedimentos pelo usuário } & $\mathrm{Sim}$ & 19 & 79,17 & 20 & 90,91 & 39 & 0,4176 \\
\hline & Não & 5 & 20,83 & 2 & 9,09 & 7 & \\
\hline \multirow{2}{*}{$\begin{array}{l}\text { 8. Como informar ao usuário para conseguir sua adesão ao } \\
\text { tratamento }\end{array}$} & $\mathrm{Sim}$ & 22 & 91,67 & 15 & 68,19 & 37 & 0,0660 \\
\hline & Não & 2 & 8,33 & 7 & 31,81 & 9 & \\
\hline \multirow{2}{*}{$\begin{array}{l}\text { 9. Omissão de informações ao usuário referentes ao seu } \\
\text { problema }\end{array}$} & Sim & 23 & 95,84 & 20 & 95,46 & 43 & 1,0000 \\
\hline & Não & 1 & 4,16 & 1 & 4,54 & 2 & \\
\hline \multirow{2}{*}{$\begin{array}{l}\text { 10. Acesso dos profissionais de saúde às informações } \\
\text { relativas à intimidade da vida familiar e conjugal }\end{array}$} & Sim & 23 & 95,84 & 18 & 86,36 & 41 & 0,3257 \\
\hline & Não & 1 & 4,16 & 3 & 13,63 & 4 & \\
\hline \multirow{2}{*}{$\begin{array}{l}\text { 11. Dificuldades para manter a privacidade nos atendimentos } \\
\text { domiciliários }\end{array}$} & Sim & 22 & 91,67 & 21 & 95,46 & 43 & 1,0000 \\
\hline & Não & 2 & 8,33 & 1 & 4,54 & 3 & \\
\hline \multirow{2}{*}{$\begin{array}{l}\text { 12. Dificuldades para o agente comunitário de saúde para } \\
\text { preservar o segredo profissional }\end{array}$} & Sim & 24 & 100,00 & 20 & 100,00 & 44 & - \\
\hline & Não & - & - & - & - & - & \\
\hline \multirow{2}{*}{$\begin{array}{l}\text { 13. Compartilhamento das informações sobre um dos } \\
\text { membros da familia com os demais }\end{array}$} & Sim & 22 & 91,67 & 20 & 100,00 & 42 & - \\
\hline & Não & 1 & 8,33 & - & - & 1 & \\
\hline \multirow{2}{*}{$\begin{array}{l}\text { 14. Limites da interferência da equipe no estilo de vida das } \\
\text { familias/usuários }\end{array}$} & Sim & 22 & 91,67 & 18 & 86,36 & 40 & 0,6521 \\
\hline & Não & 2 & 8,33 & 3 & 13,63 & 5 & \\
\hline \multirow{2}{*}{$\begin{array}{l}\text { 15. Atitude do médico frente aos valores religiosos próprios e } \\
\text { dos usuários }\end{array}$} & $\operatorname{Sim}$ & 22 & 91,67 & 19 & 86,36 & 41 & 0,6651 \\
\hline & Não & 2 & 8,33 & 3 & 13,63 & 5 & \\
\hline \multirow{2}{*}{$\begin{array}{l}\text { 16. Solicitação de procedimentos por menores de idade sem } \\
\text { autorização ou conhecimento dos pais }\end{array}$} & $\mathrm{Sim}$ & 22 & 95,84 & 21 & 95,46 & 43 & 1,0000 \\
\hline & Não & 1 & 4,16 & 1 & 4,54 & 2 & \\
\hline \multirow{2}{*}{ 17. Recusa dos usuários às indicações médicas } & Sim & 19 & 79,17 & 19 & 86,36 & 38 & 0,7021 \\
\hline & Não & 5 & 20,83 & 3 & 13,63 & 8 & \\
\hline \multirow{2}{*}{$\begin{array}{l}\text { 18. Discussão de detalhes da situação clínica do usuário na } \\
\text { sua frente }\end{array}$} & Sim & 15 & 66,67 & 21 & 95,46 & 36 & 0,1177 \\
\hline & Não & 8 & 33,33 & 1 & 4,54 & 9 & \\
\hline
\end{tabular}


Tanto enfermeiros quanto médicos, parecem reconhecer a importância do respeito nas relações com os usuários e as famílias, já que o "desrespeito do profissional para com o usuário" foi considerado como problema ético por todos, independentemente da categoria profissional. A preservação da privacidade também parece essencial, uma vez que todos os enfermeiros e médicos apontaram como problema ético "dificuldades para o agente comunitário de saúde preservar o segredo profissional".

A privacidade e o respeito tocam em conceitos bastante claros na ética em saúde. Estudos em Israel (12) e nos EUA ${ }^{(11)}$ apontaram o desrespeito das equipes de saúde para com os usuários como situações geradoras de problemas éticos. Outra pesquisa, com mulheres em situação de exclusão social, entre 18 e 60 anos, nos EUA, aponta que estas encontraram dificuldades no acesso aos serviços de saúde e quando o conseguiram, foram vítimas de desrespeito ${ }^{(13)}$, com trato ríspido ou preconceituoso.

A proposta do PSF de formação de vínculo entre a equipe de saúde e os usuários e/ou famílias, pressupõe uma relação de diálogo que se estabelece entre pessoas que se reconhecem e se respeitam como sujeitos. U m comportamento de desrespeito pode ameaçar a relação de vínculo e de co-responsabilização pela saúde dos usuários.

0 problema ético do desrespeito parece trazer à tona a imprevisibilidade de resultados que é inerente às relações que marcam o encontro entre usuários e trabalhadores, no qual entra em jogo um confronto de diferentes interesses. De um lado o usuário busca a resolução de um problema de saúde que considera importante e do outro, o trabalhador, muitas vezes, mantém-se preso a procedimentos, normas e rotinas do serviço ou ainda a seu entendimento técnico do que é melhor para o usuário. Neste desencontro de necessidades e interesses, a negociação é imprescindível, pois nem sempre o carecimento do usuário é interpretado como um problema pelo profissional e/ou para o serviço de saúde ${ }^{(14,15,16)}$.

O espaço relacional e comunicacional dos profissionais de saúde com as famílias/usuários caracteriza-se por um movimento que pode ser, por meio de uma linguagem simbólica, representado pela "roda da vida" que gira entre movimentos de al tos e baixos, de aberturas e fechamentos, de expansões e contrações, exigindo de nós, seres humanos e profissionais de saúde, flexibilidade para entender a dinâmica desses movimentos. Permitir que nossas diferentes experiências, valores de vida e diferentes entendimentos de ser no mundo se toquem e se fundam parece ser um esforço importante para o compartilhamento e a abertura dos horizontes normativos ${ }^{(17)}$.

A comunicação é indispensável para a assistência à saúde, pois, além de principal meio de veiculação do processo educativo, constitui-se recurso para estabel ecer a confiança e a vinculação do usuário à equipe e ao serviço. Os profissionais de saúde devem incluir entre seus conhecimentos técnicos os relativos à comunicação, entretanto a tecnologia das relações é uma das mais complexas por abranger não somente conhecimentos, habilidades e comportamentos, mas, requerer, sobretudo, atitudes de respeito entre pessoas. As autoras afirmam que a comunicação na atenção à saúde configura uma ação intencional dirigida e orientada para um interesse concreto, sendo "al go que se constrói" com base na escuta do outro para compreender quais são suas crenças, sua situação e suas possibilidades, com vistas a poder atuar conjuntamente. Esta abordagem dialógica e emancipatória tem como um dos seus pressupostos acreditar que todas as pessoas têm 0 direito a escolher 0 caminho mais apropriado para promover, manter e recuperar sua saúde ${ }^{(18)}$.

As três situações consideradas como problemas éticos que registraram maior freqüência de ocorrência, independentemente da categoria profissional, também tocam na questão do respeito devido aos usuários como sujeitos autônomos, destacando-se os aspectos do preconceito, informação e capacidade para tomada de decisão, Tabela 2, na página seguinte.

Dentre os problemas mais freqüentes, tanto para enfermeiros quanto para médicos, aparece a "recusa dos usuários às indicações médicas". D esta forma, é óbvio, outro problema bastante vivido ser "como informar 0 paciente para conseguir sua adesão ao tratamento".

A tensão que cerca a relação equipe-usuário/ famílias fica mais patente ao consideramos que "solicitação de procedimentos por menores de idade sem autorização ou conhecimento dos pais" também está entre os problemas éticos mais freqüentes.

Estes problemas éticos reiteram a urgência de se pautar a relação profissional-usuário por um processo de comunicação que vise compartil har decisões e projetos de vida, não se restringindo a esclarecimentos sobre tratamentos e exames. Em outras palavras, a equipe de PSF tem que voltar suas ações para o que ${ }^{(17)}$ denomina como 0 "A Ifabeto do B om Cuidado", composto de quatro atitudes: calor humano, respeito, confiança e envolvimento.

\subsection{PROBLEMAS ÉTICOS NAS RELAÇÕES DA EQUIPE DE PSF}

A equipe de saúde é uma rede de relações tecida no cotidiano, entre suj eitos com diferentes saberes e que desenvolvem diferentes práticas, o que requer certa disponibilidade para reconhecerem e respeitarem tais diferenças ${ }^{(15)}$. A s situações eticamente significativas ou problemáticas, vivenciadas na saúde da família, em sua maioria, envolvem mais de um profissional ou a equipe como um todo (19). 
Tabela 2 - Distribuição e associação da ocorrência dos problemas éticos nas relações com os usuários e as famílias segundo categoria profissional. São Paulo, 2004-2005

\begin{tabular}{|c|c|c|c|c|c|c|c|}
\hline \multirow{2}{*}{$\begin{array}{l}\text { Problema } \\
\text { 1. Dificuldade em estabelecer os limites da relação profissional- } \\
\text { usuário }\end{array}$} & \multirow{2}{*}{$\begin{array}{c}\text { Freqüência } \\
\text { Já ocorreu } \\
\text { Nunca ocorreu }\end{array}$} & \multicolumn{2}{|c|}{ Enfermeiros $\left(n^{0}-\%\right)$} & \multicolumn{2}{|c|}{ Médicos $\left(n^{0}-\%\right)$} & \multirow{2}{*}{$\begin{array}{c}\text { Total } \\
29 \\
9\end{array}$} & \multirow{2}{*}{$\frac{\mathbf{p}}{0,6040}$} \\
\hline & & $\begin{array}{c}14 \\
6\end{array}$ & $\begin{array}{l}70,00 \\
30,00\end{array}$ & $\begin{array}{l}15 \\
3\end{array}$ & $\begin{array}{l}83,40 \\
16,60\end{array}$ & & \\
\hline 2. Pré-julgamento dos usuários dos serviço por parte das equipes & $\begin{array}{l}\text { Já ocorreu } \\
\text { Nunca ocorreu }\end{array}$ & $\begin{array}{l}19 \\
2\end{array}$ & $\begin{array}{l}90,50 \\
9,50\end{array}$ & $\begin{array}{l}16 \\
4\end{array}$ & $\begin{array}{l}80,00 \\
20,00\end{array}$ & $\begin{array}{c}35 \\
6\end{array}$ & 0,6350 \\
\hline 3. Desrespeito do profissional para com o usuário & $\begin{array}{l}\text { Já ocorreu } \\
\text { Nunca ocorreu }\end{array}$ & $\begin{array}{l}16 \\
8\end{array}$ & $\begin{array}{l}66,70 \\
33,30\end{array}$ & $\begin{array}{l}14 \\
7\end{array}$ & $\begin{array}{l}66,70 \\
33,30\end{array}$ & $\begin{array}{l}30 \\
15\end{array}$ & 0,9480 \\
\hline 4. Indicações clínicas inadequadas & $\begin{array}{l}\text { Já ocorreu } \\
\text { Nunca ocorreu }\end{array}$ & $\begin{array}{l}12 \\
9\end{array}$ & $\begin{array}{l}57,20 \\
42,90\end{array}$ & $\begin{array}{l}15 \\
4\end{array}$ & $\begin{array}{l}79,00 \\
21,00\end{array}$ & $\begin{array}{l}27 \\
13\end{array}$ & 0,2380 \\
\hline $\begin{array}{l}\text { 5. Prescrição de medicamentos que o usuário não poderá } \\
\text { comprar }\end{array}$ & $\begin{array}{l}\text { Já ocorreu } \\
\text { Nunca ocorreu }\end{array}$ & $\begin{array}{c}14 \\
5\end{array}$ & $\begin{array}{l}73,70 \\
26,30\end{array}$ & $\begin{array}{l}14 \\
3\end{array}$ & $\begin{array}{l}82,30 \\
17,60\end{array}$ & $\begin{array}{c}28 \\
8\end{array}$ & 0,3480 \\
\hline $\begin{array}{l}\text { 6. Prescrição de medicamentos mais caros com eficiência igual a } \\
\text { dos mais baratos }\end{array}$ & $\begin{array}{l}\text { Já ocorreu } \\
\text { Nunca ocorreu }\end{array}$ & $\begin{array}{c}4 \\
15\end{array}$ & $\begin{array}{l}21,10 \\
78,90\end{array}$ & $\begin{array}{l}10 \\
9\end{array}$ & $\begin{array}{l}52,70 \\
47,40\end{array}$ & $\begin{array}{l}14 \\
24\end{array}$ & 0,1160 \\
\hline 7. Solicitação de procedimentos pelo usuário & $\begin{array}{l}\text { Já ocorreu } \\
\text { Nunca ocorreu }\end{array}$ & $\begin{array}{l}17 \\
2\end{array}$ & $\begin{array}{l}89,40 \\
10,50\end{array}$ & $\begin{array}{l}17 \\
3\end{array}$ & $\begin{array}{l}85,00 \\
15,00\end{array}$ & $\begin{array}{c}34 \\
5\end{array}$ & 0,4300 \\
\hline $\begin{array}{l}\text { 8. Como informar ao usuário para conseguir sua adesão ao } \\
\text { tratamento }\end{array}$ & $\begin{array}{l}\text { Já ocorreu } \\
\text { Nunca ocorreu }\end{array}$ & $\begin{array}{l}14 \\
7\end{array}$ & $\begin{array}{l}66,60 \\
33,30\end{array}$ & $\begin{array}{c}13 \\
1\end{array}$ & $\begin{array}{l}92,80 \\
7,20\end{array}$ & $\begin{array}{c}27 \\
8\end{array}$ & 0,1850 \\
\hline $\begin{array}{l}\text { 9. Omissão de informações ao usuário referentes ao seu } \\
\text { problema }\end{array}$ & $\begin{array}{l}\text { Já ocorreu } \\
\text { Nunca ocorreu }\end{array}$ & $\begin{array}{c}8 \\
15\end{array}$ & $\begin{array}{l}34,70 \\
65,20\end{array}$ & $\begin{array}{l}9 \\
11\end{array}$ & $\begin{array}{l}45,00 \\
55,00\end{array}$ & $\begin{array}{l}17 \\
26\end{array}$ & 0,6240 \\
\hline $\begin{array}{l}\text { 10. Acesso dos profissionais de saúde às informações relativas à } \\
\text { intimidade da vida familiar e conjugal }\end{array}$ & $\begin{array}{l}\text { Já ocorreu } \\
\text { Nunca ocorreu }\end{array}$ & $\begin{array}{c}20 \\
3\end{array}$ & $\begin{array}{l}87,00 \\
13,00\end{array}$ & $\begin{array}{l}15 \\
3\end{array}$ & $\begin{array}{l}83,40 \\
16,70\end{array}$ & $\begin{array}{c}35 \\
6\end{array}$ & 0,9280 \\
\hline $\begin{array}{l}\text { 11. Dificuldades para manter a privacidade nos atendimentos } \\
\text { domiciliários }\end{array}$ & $\begin{array}{l}\text { Já ocorreu } \\
\text { Nunca ocorreu }\end{array}$ & $\begin{array}{l}19 \\
3\end{array}$ & $\begin{array}{l}86,40 \\
13,60\end{array}$ & $\begin{array}{l}17 \\
4\end{array}$ & $\begin{array}{l}81,00 \\
19,00\end{array}$ & $\begin{array}{l}36 \\
7\end{array}$ & 0,8670 \\
\hline $\begin{array}{l}\text { 12. Dificuldades para o agente comunitário de saúde preservar o } \\
\text { segredo profissional }\end{array}$ & $\begin{array}{l}\text { Já ocorreu } \\
\text { Nunca ocorreu }\end{array}$ & $\begin{array}{c}17 \\
6\end{array}$ & $\begin{array}{l}73,90 \\
26,10\end{array}$ & $\begin{array}{l}16 \\
4\end{array}$ & $\begin{array}{l}80,00 \\
20,00\end{array}$ & $\begin{array}{l}33 \\
10\end{array}$ & 0,7270 \\
\hline $\begin{array}{l}\text { 13. Compartilhamento das informações sobre um dos membros } \\
\text { da familia com os demais }\end{array}$ & $\begin{array}{l}\text { Já ocorreu } \\
\text { Nunca ocorreu }\end{array}$ & $\begin{array}{l}15 \\
7\end{array}$ & $\begin{array}{l}68,20 \\
31,80\end{array}$ & $\begin{array}{l}18 \\
4\end{array}$ & $\begin{array}{l}81,80 \\
18,20\end{array}$ & $\begin{array}{l}33 \\
11\end{array}$ & 0,5780 \\
\hline $\begin{array}{l}\text { 14. Limites da interferência da equipe no estilo de vida das } \\
\text { famílias/usuários }\end{array}$ & $\begin{array}{l}\text { Já ocorreu } \\
\text { Nunca ocorreu }\end{array}$ & $\begin{array}{l}19 \\
3\end{array}$ & $\begin{array}{l}86,40 \\
13,60\end{array}$ & $\begin{array}{l}14 \\
4\end{array}$ & $\begin{array}{l}77,80 \\
22,20\end{array}$ & $\begin{array}{l}33 \\
7\end{array}$ & 0,7580 \\
\hline $\begin{array}{l}\text { 15. Atitude do médico frente aos valores religiosos próprios e } \\
\text { dos usuários }\end{array}$ & $\begin{array}{l}\text { Já ocorreu } \\
\text { Nunca ocorreu }\end{array}$ & $\begin{array}{c}7 \\
14\end{array}$ & $\begin{array}{l}33,30 \\
66,70\end{array}$ & $\begin{array}{c}6 \\
13\end{array}$ & $\begin{array}{l}31,60 \\
68,40\end{array}$ & $\begin{array}{l}13 \\
27\end{array}$ & 0,9060 \\
\hline $\begin{array}{l}\text { 16. Solicitação de procedimentos por menores de idade sem } \\
\text { autorização ou conhecimento dos pais }\end{array}$ & $\begin{array}{l}\text { Já ocorreu } \\
\text { Nunca ocorreu }\end{array}$ & $\begin{array}{l}14 \\
8\end{array}$ & $\begin{array}{l}63,60 \\
36,40\end{array}$ & $\begin{array}{c}12 \\
9\end{array}$ & $\begin{array}{l}57,10 \\
42,90\end{array}$ & $\begin{array}{l}26 \\
17\end{array}$ & 0,8890 \\
\hline 17. Recusa dos usuários às indicações médicas & $\begin{array}{l}\text { Já ocorreu } \\
\text { Nunca ocorreu }\end{array}$ & $\begin{array}{c}18 \\
1\end{array}$ & $\begin{array}{c}94,70 \\
5,30\end{array}$ & $\begin{array}{c}18 \\
1\end{array}$ & $\begin{array}{c}94,70 \\
5,30\end{array}$ & $\begin{array}{l}36 \\
2\end{array}$ & 0,7250 \\
\hline $\begin{array}{l}\text { 18. Discussão de detalhes da situação clínica do usuário na sua } \\
\text { frente }\end{array}$ & $\begin{array}{l}\text { Já ocorreu } \\
\text { Nunca ocorreu }\end{array}$ & $\begin{array}{l}16 \\
7\end{array}$ & $\begin{array}{l}69,60 \\
30,40\end{array}$ & $\begin{array}{c}15 \\
6\end{array}$ & $\begin{array}{l}71,40 \\
28,60\end{array}$ & $\begin{array}{l}31 \\
13\end{array}$ & 0,6370 \\
\hline $\begin{array}{l}\text { 19. Não solicitação de consentimento da familia para relatar sua } \\
\text { história em publicação científica }\end{array}$ & $\begin{array}{c}\text { Já ocorreu } \\
\text { Nunca ocorreu }\end{array}$ & $\begin{array}{c}2 \\
20 \\
\end{array}$ & $\begin{array}{r}9,10 \\
90,90 \\
\end{array}$ & $\begin{array}{c}2 \\
19 \\
\end{array}$ & $\begin{array}{c}9,50 \\
90,50 \\
\end{array}$ & $\begin{array}{c}4 \\
39 \\
\end{array}$ & 0,5130 \\
\hline
\end{tabular}

No PSF, a identidade dos sujeitos envolvidos no trabalho é menos clara do que nos demais serviços de saúde, gerando conflito entre os profissionais ${ }^{(16)}$. Somase a isso a conformação da equipe, que incorpora 0 A gente Comunitário de Saúde, além da proporção enfermeiro/médico para cada equipe, que, diferente do que ocorre em unidades de saúde organizadas na lógica programática, em que essa relação é de um enfermeiro para cada três médicos. As relações de equipe são importantes para a boa qualidade da atenção prestada pelo serviço de saúde, mas, por vezes, constituem-se fontes de problemas éticos, como apontado na tabela 3. 
Tabela 3 - Distribuição e associação da percepção das situações listadas como problemas éticos nas relações de equipe segundo categoria profissional. São Paulo, 2004-2005

\begin{tabular}{|c|c|c|c|c|c|c|c|}
\hline Situação & Problema & Enferm & $\left(n^{0}-\%\right)$ & Méd & $\left(n^{0}-\%\right)$ & Total & p \\
\hline $\begin{array}{l}\text { 1. Falta de compromisso dos profissionais que } \\
\text { atuam no PSF com o serviço }\end{array}$ & $\begin{array}{l}\text { Sim } \\
\text { Não }\end{array}$ & $\begin{array}{c}21 \\
2\end{array}$ & $\begin{array}{c}91,67 \\
8,33\end{array}$ & $\begin{array}{c}21 \\
1\end{array}$ & $\begin{array}{c}95,46 \\
4,54\end{array}$ & $\begin{array}{c}42 \\
3\end{array}$ & 1,0000 \\
\hline $\begin{array}{l}\text { 2. Falta de companheirismo e colaboração entre as } \\
\text { equipes }\end{array}$ & $\begin{array}{l}\text { Sim } \\
\text { Não }\end{array}$ & $\begin{array}{c}22 \\
2\end{array}$ & $\begin{array}{c}91,67 \\
8,33\end{array}$ & $\begin{array}{c}20 \\
2\end{array}$ & $\begin{array}{c}90,91 \\
9,09\end{array}$ & $\begin{array}{c}42 \\
4\end{array}$ & 1,0000 \\
\hline 3. Desrespeito entre os integrantes da equipe & $\begin{array}{l}\text { Sim } \\
\text { Não }\end{array}$ & $\begin{array}{c}22 \\
2\end{array}$ & $\begin{array}{c}91,67 \\
8,33\end{array}$ & 22 & $\begin{array}{c}100,00 \\
-\end{array}$ & $\begin{array}{c}44 \\
2\end{array}$ & - \\
\hline $\begin{array}{l}\text { 4. Desprepraro dos profissionais para trabalhar no } \\
\text { PSF }\end{array}$ & $\begin{array}{l}\text { Sim } \\
\text { Não }\end{array}$ & $\begin{array}{l}17 \\
7\end{array}$ & $\begin{array}{l}70,84 \\
29,16\end{array}$ & $\begin{array}{c}20 \\
2\end{array}$ & $\begin{array}{c}90,91 \\
9,09\end{array}$ & $\begin{array}{c}37 \\
9\end{array}$ & 0,1385 \\
\hline $\begin{array}{l}\text { 5. Dificuldades para delimitar as especificidades e } \\
\text { responsabilidades de cada profissional }\end{array}$ & $\begin{array}{l}\text { Sim } \\
\text { Não }\end{array}$ & $\begin{array}{c}21 \\
3\end{array}$ & $\begin{array}{l}87,50 \\
12,50\end{array}$ & $\begin{array}{c}21 \\
1\end{array}$ & $\begin{array}{c}95,46 \\
4,54\end{array}$ & $\begin{array}{c}42 \\
4\end{array}$ & 0,6093 \\
\hline $\begin{array}{l}\text { 6. Omissão dos profissionais frente à indicação } \\
\text { clínica imprecisa }\end{array}$ & $\begin{array}{l}\text { Sim } \\
\text { Não }\end{array}$ & $\begin{array}{l}24 \\
-\end{array}$ & $\begin{array}{c}100,00 \\
-\end{array}$ & $\begin{array}{c}21 \\
1\end{array}$ & $\begin{array}{c}95,46 \\
4,54\end{array}$ & $\begin{array}{r}45 \\
1\end{array}$ & - \\
\hline $\begin{array}{l}\text { 7. Compartilhamento das informações relativas ao } \\
\text { usuário e familia no âmbito da equipe do PSF }\end{array}$ & $\begin{array}{l}\text { Sim } \\
\text { Não }\end{array}$ & $\begin{array}{l}20 \\
4\end{array}$ & $\begin{array}{l}83,34 \\
16,66\end{array}$ & $\begin{array}{c}19 \\
3\end{array}$ & $\begin{array}{l}86,36 \\
13,63\end{array}$ & $\begin{array}{l}39 \\
7\end{array}$ & 1,0000 \\
\hline $\begin{array}{l}\text { 8. Não solicitação de consentimento da família para } \\
\text { relatar sua história em publicação científica }\end{array}$ & $\begin{array}{l}\text { Sim } \\
\text { Não }\end{array}$ & $\begin{array}{c}22 \\
2\end{array}$ & $\begin{array}{c}91,67 \\
8,33\end{array}$ & $\begin{array}{c}21 \\
1\end{array}$ & $\begin{array}{c}95,46 \\
4,54\end{array}$ & $\begin{array}{c}43 \\
3\end{array}$ & 1,0000 \\
\hline $\begin{array}{l}\text { 9. Questionamento da prescrição médica por parte } \\
\text { de funcionários da USF }\end{array}$ & $\begin{array}{l}\text { Sim } \\
\text { Não }\end{array}$ & $\begin{array}{l}24 \\
-\end{array}$ & $\begin{array}{c}100,00 \\
-\end{array}$ & $\begin{array}{c}22 \\
-\end{array}$ & $\begin{array}{c}100,00 \\
-\end{array}$ & $\begin{array}{l}46 \\
-\end{array}$ & - \\
\hline $\begin{array}{l}\text { 10. Quebra do sigilo médico por outros membros } \\
\text { da equipe ao publicarem relato de casos }\end{array}$ & $\begin{array}{l}\text { Sim } \\
\text { Não }\end{array}$ & $\begin{array}{c}24 \\
-\end{array}$ & $\begin{array}{c}100,00 \\
-\end{array}$ & $\begin{array}{c}22 \\
-\end{array}$ & $\begin{array}{c}100,00 \\
-\end{array}$ & $\begin{array}{l}46 \\
-\end{array}$ & - \\
\hline $\begin{array}{l}\text { 11. Não solicitação de consentimento da equipe } \\
\text { para relatar caso em publicação cinetífica }\end{array}$ & $\begin{array}{l}\text { Sim } \\
\text { Não }\end{array}$ & $\begin{array}{c}23 \\
1\end{array}$ & $\begin{array}{c}95,84 \\
4,16\end{array}$ & $\begin{array}{c}20 \\
1\end{array}$ & $\begin{array}{c}95,46 \\
4,54\end{array}$ & $\begin{array}{c}43 \\
2\end{array}$ & 1,0000 \\
\hline
\end{tabular}

$\mathrm{Na}$ tabela 3, chamam atenção as situações "questionamento da prescrição médica por parte dos funcionários da USF" ea "quebra do sigilo médico por outros membros da equipe ao publicarem relato de casos" por terem sido consideradas como problemas de ordem ética por todos os sujeitos participantes do estudo, independente da categoria profissional. Dessa forma, percebe-seque os sujeitos do estudo acreditam que compartilhar informações entre os membros da equipe é um problema de ordem ética, daí a própria situação "compartilhamento das informações relativos aos usuários e famílias no âmbito da equipe do PSF" também ser apontado como problema.

O compartilhamento de informações dentro da equipe é fundamental para a qualidade dos serviços prestados às famílias. Porém, como preconiza Fortes ${ }^{(20)}$, o fato do trabal ho ser multiprofissional não significa que todos os membros da equipe devam ter acesso a todas as informações referentes a um usuário. A ssim, cada profissional deve ter acesso apenas à informações necessárias para realizar suas atividades em benefício do usuário e/ou família, o queé percebido e requerido pelos usuários.

Ainda em relação à tabela 3, outra situação que se destacaéa "omissão dos profissionais frenteà indicação clínica imprecisa" por ter sido indicada pela maioria dos sujeitos participantes desseestudo como problema ético, independente da categoria profissional.

Na omissão dos profissionais frente à indicação clínica imprecisa, os profissionais vivenciam uma oposição entre o dever de proteger o usuário contra atos potencialmente prejudiciais eo temor de comprometer as relações com a equipe. $N$ ão é raro, entre os profissionais de saúde, especialmente a enfermagem, o entendimento dequepor uma "questão deética" não se deve criticar os colegas e outros membros da equipe (21). As situações de "despreparo dos profissionais para trabal har no PSF" e "dificuldades para delimitar as especificidades e responsabilidades de cada profissional" 
Tabela 4 - Distribuição e associação da ocorrência dos problemas éticos nas relações com a equipe segundo categoria profissional. São Paulo, 2004-2005

\begin{tabular}{|c|c|c|c|c|c|c|c|}
\hline Problema & Freqüência & \multicolumn{2}{|c|}{ Enfermeiros $\left(n^{0}-\%\right)$} & \multicolumn{2}{|c|}{ Médicos $\left(n^{0}-\%\right)$} & Total & p \\
\hline $\begin{array}{l}\text { 1. Falta de compromisso dos profissionais que } \\
\text { atuam no PSF com o serviço }\end{array}$ & $\begin{array}{c}\text { Já ocorreu } \\
\text { Nunca ocorreu }\end{array}$ & $\begin{array}{l}14 \\
7\end{array}$ & $\begin{array}{l}66,70 \\
33,30\end{array}$ & $\begin{array}{l}17 \\
4\end{array}$ & $\begin{array}{l}81,00 \\
19,00\end{array}$ & $\begin{array}{l}31 \\
11\end{array}$ & 0,5240 \\
\hline $\begin{array}{l}\text { 2. Falta de companheirismo e colaboração } \\
\text { entre as equipes }\end{array}$ & $\begin{array}{l}\text { Já ocorreu } \\
\text { Nunca ocorreu }\end{array}$ & $\begin{array}{l}15 \\
7\end{array}$ & $\begin{array}{l}68,20 \\
31,80\end{array}$ & $\begin{array}{l}17 \\
3\end{array}$ & $\begin{array}{l}85,00 \\
15,00\end{array}$ & $\begin{array}{l}32 \\
10\end{array}$ & 0,4290 \\
\hline 3. Desrespeito entre os integrantes da equipe & $\begin{array}{c}\text { Já ocorreu } \\
\text { Nunca ocorreu }\end{array}$ & $\begin{array}{c}14 \\
8\end{array}$ & $\begin{array}{l}63,60 \\
36,40\end{array}$ & $\begin{array}{l}17 \\
5\end{array}$ & $\begin{array}{l}77,30 \\
22,70\end{array}$ & $\begin{array}{l}31 \\
13\end{array}$ & 0,4720 \\
\hline $\begin{array}{l}\text { 4. Desprepraro dos profissionais para trabalhar } \\
\text { no PSF }\end{array}$ & $\begin{array}{c}\text { Já ocorreu } \\
\text { Nunca ocorreu }\end{array}$ & $\begin{array}{l}17 \\
-\end{array}$ & $\begin{array}{c}100,00 \\
-\end{array}$ & $\begin{array}{c}19 \\
1\end{array}$ & $\begin{array}{c}95,00 \\
5,00\end{array}$ & $\begin{array}{c}36 \\
1\end{array}$ & 0,5920 \\
\hline $\begin{array}{l}\text { 5. Dificuldades para delimitar as especificidades } \\
\text { e responsabilidades de cada profissional }\end{array}$ & $\begin{array}{l}\text { Já ocorreu } \\
\text { Nunca ocorreu }\end{array}$ & $\begin{array}{l}17 \\
4\end{array}$ & $\begin{array}{l}81,00 \\
19,00\end{array}$ & $\begin{array}{c}20 \\
1\end{array}$ & $\begin{array}{c}95,20 \\
4,80\end{array}$ & $\begin{array}{c}37 \\
5\end{array}$ & 0,2880 \\
\hline $\begin{array}{l}\text { 6. Omissão dos profissionais frente à indicação } \\
\text { clínica imprecisa }\end{array}$ & $\begin{array}{c}\text { Já ocorreu } \\
\text { Nunca ocorreu }\end{array}$ & $\begin{array}{c}9 \\
15\end{array}$ & $\begin{array}{l}37,50 \\
62,50\end{array}$ & $\begin{array}{l}12 \\
9\end{array}$ & $\begin{array}{l}57,10 \\
42,90\end{array}$ & $\begin{array}{l}21 \\
24\end{array}$ & 0,1320 \\
\hline $\begin{array}{l}\text { 7. Compartilhamento das informações relativas } \\
\text { ao usuário e familia no âmbito da equipe do } \\
\text { PSF }\end{array}$ & $\begin{array}{c}\text { Já ocorreu } \\
\text { Nunca ocorreu }\end{array}$ & $\begin{array}{c}17 \\
3\end{array}$ & $\begin{array}{l}85,00 \\
15,00\end{array}$ & $\begin{array}{l}17 \\
2\end{array}$ & $\begin{array}{l}89,50 \\
10,50\end{array}$ & $\begin{array}{c}34 \\
5\end{array}$ & 0,5360 \\
\hline $\begin{array}{l}\text { 8. Questionamento da prescrição médica por } \\
\text { parte de funcionários da USF }\end{array}$ & $\begin{array}{c}\text { Já ocorreu } \\
\text { Nunca ocorreu }\end{array}$ & $\begin{array}{c}16 \\
8\end{array}$ & $\begin{array}{l}66,70 \\
33,30\end{array}$ & $\begin{array}{l}17 \\
5\end{array}$ & $\begin{array}{l}77,30 \\
22,70\end{array}$ & $\begin{array}{l}33 \\
13\end{array}$ & 0,3590 \\
\hline $\begin{array}{l}\text { 9. Quebra do sigilo médico por outros } \\
\text { membros da equipe ao publicarem relato de } \\
\text { casos }\end{array}$ & $\begin{array}{c}\text { Já ocorreu } \\
\text { Nunca ocorreu }\end{array}$ & $\begin{array}{c}6 \\
18\end{array}$ & $\begin{array}{l}25,00 \\
75,00\end{array}$ & $\begin{array}{c}5 \\
17\end{array}$ & $\begin{array}{l}22,70 \\
77,30\end{array}$ & $\begin{array}{l}11 \\
35\end{array}$ & 0,9590 \\
\hline $\begin{array}{l}\text { 10. Não solicitação de consentimento da } \\
\text { equipe para relatar caso em publicação } \\
\text { científica }\end{array}$ & $\begin{array}{c}\text { Já ocorreu } \\
\text { Nunca ocorreu }\end{array}$ & $\begin{array}{c}3 \\
20\end{array}$ & $\begin{array}{l}13,00 \\
87,00\end{array}$ & - & 100,00 & $\begin{array}{c}3 \\
40\end{array}$ & 0,0940 \\
\hline
\end{tabular}

aparecem com bastante freqüência entre os problemas éticos mais vividos nas relações com a equipe, agravando os demais problemas registrados neste tipo de relação (Tabela 4).

Estudo realizado com enfermeiros distritais e visitadores, na Inglaterra, revel ou que ambos se preocupam com a falta de treinamento para se envolverem em atividades de promoção à saúde, já que ao serem entrevistados esta ainda era um prática nova para grande parte deles ${ }^{(22) .}$

As dificuldades para delimitar especificidades e responsabilidades de cada profissional, acarretam conflitos entre enfermeiros e médicos, tornando-se necessário que cada um defina suas atribuições e responsabilidades de forma mútua, discutindo conjuntamente sobre as questões de qualificação e competência (23).

\subsection{PROBLEMAS ÉTICOS NAS RELAÇÕES COM A ORGANIZAÇÃO E O SISTEMA DE SAÚDE}

A o se considerar que o Sistema Ú nico de Saúde ainda encontra-se em fase de consolidação de sua implantação e, mais especificamente, em São Paulo experimentou anos de desmonte da rede pública de saúde e se for acrescentado a isto que o PSF é uma estratégia relativamente nova para a reorganização da atenção básica, não deve causar estranheza que boa parte dos problemas éticos vividos pelos enfermeiros e médicos sejam decorrentes de aspectos organizacionais, tanto no âmbito da própria USF quanto do sistema e da rede de saúde, como se observa na tabela 5 , na página seguinte.

Os enfermeiros e médicos que participaram desse estudo consideraram com maior freqüência "dificul dade para preservar privacidade por problemas na estrutura física e rotinas da USF", "falta de apoio estrutural para discutir e resolver os problemas éticos" e "falta de transparência da direção da USF na resolução de problemas com os profissionais" como situações geradoras de problemas éticos.

N ovamente a questão da privacidade é apontada como um problema ético pelos profissionais, tanto enfermeiros como médicos, pois esta não fica totalmente restrita às atitudes dos trabal hadores que têm acesso às 
Tabela 5 - Distribuição e associação da percepção das situações listadas como problemas éticos nas relações com a organização e o sistema de saúde segundo categoria profissional. São Paulo, 2004-2005

\begin{tabular}{|c|c|c|c|c|c|c|c|}
\hline Situação & Problema & Enfern & $\left(n^{0}-\%\right)$ & Médic & $\left(n^{0}-\%\right)$ & Total & $\mathbf{p}$ \\
\hline $\begin{array}{l}\text { 1. Dificuldades para preservar privacidade por problemas na } \\
\text { estrutura física e rotinas da USF }\end{array}$ & $\begin{array}{l}\text { Sim } \\
\text { Não }\end{array}$ & $\begin{array}{c}23 \\
1\end{array}$ & $\begin{array}{c}95,84 \\
4,16\end{array}$ & $\begin{array}{l}22 \\
-\end{array}$ & $\begin{array}{c}100,00 \\
-\end{array}$ & $\begin{array}{c}45 \\
1\end{array}$ & - \\
\hline $\begin{array}{l}\text { 2. Falta de apoio estrtutural para discutir e resolver os } \\
\text { problemas éticos }\end{array}$ & $\begin{array}{l}\text { Sim } \\
\text { Não }\end{array}$ & $\begin{array}{c}21 \\
1\end{array}$ & $\begin{array}{c}95,84 \\
4,16\end{array}$ & $\begin{array}{l}22 \\
-\end{array}$ & 100,00 & $\begin{array}{c}43 \\
1\end{array}$ & - \\
\hline $\begin{array}{l}\text { 3. Falta de transparência da direção da USF na resolução de } \\
\text { problemas com profissionais }\end{array}$ & $\begin{array}{l}\text { Sim } \\
\text { Não }\end{array}$ & $\begin{array}{c}23 \\
1\end{array}$ & $\begin{array}{c}95,84 \\
4,16\end{array}$ & $\begin{array}{c}21 \\
1\end{array}$ & $\begin{array}{c}95,46 \\
4,54\end{array}$ & $\begin{array}{c}44 \\
2\end{array}$ & 1,0000 \\
\hline 4. Excesso de familias adscritas para cada equipe & $\begin{array}{l}\text { Sim } \\
\text { Não }\end{array}$ & $\begin{array}{l}23 \\
-\end{array}$ & $\begin{array}{c}100,00 \\
-\end{array}$ & $\begin{array}{c}14 \\
8\end{array}$ & $\begin{array}{l}63,64 \\
36,36\end{array}$ & $\begin{array}{c}37 \\
8\end{array}$ & 0,6262 \\
\hline 5. Restrição do acesso dos usuários aos serviços & $\begin{array}{l}\text { Sim } \\
\text { Não }\end{array}$ & $\begin{array}{c}18 \\
6\end{array}$ & $\begin{array}{l}75,00 \\
25,00\end{array}$ & $\begin{array}{c}20 \\
2\end{array}$ & $\begin{array}{c}90,91 \\
9,09\end{array}$ & $\begin{array}{c}38 \\
8\end{array}$ & 0,2469 \\
\hline 6. Demérito dos encaminhamentos feitos pelos médicos do PSF & $\begin{array}{l}\text { Sim } \\
\text { Não }\end{array}$ & $\begin{array}{c}21 \\
3\end{array}$ & $\begin{array}{l}87,50 \\
12,50\end{array}$ & $\begin{array}{c}22 \\
-\end{array}$ & $\begin{array}{c}100,00 \\
-\end{array}$ & $\begin{array}{c}43 \\
3\end{array}$ & - \\
\hline 7. Dificuldades no acesso a exames complementares & $\begin{array}{l}\text { Sim } \\
\text { Não }\end{array}$ & $\begin{array}{c}19 \\
5\end{array}$ & $\begin{array}{l}79,17 \\
20,83\end{array}$ & $\begin{array}{c}19 \\
3\end{array}$ & $\begin{array}{l}86,36 \\
13,63\end{array}$ & $\begin{array}{c}38 \\
8\end{array}$ & 0,7021 \\
\hline $\begin{array}{l}\text { 8. Dificuldades quanto ao retorno e confiabilidade dos } \\
\text { resultados de exames laboratoriais }\end{array}$ & $\begin{array}{l}\text { Sim } \\
\text { Não }\end{array}$ & $\begin{array}{c}21 \\
3\end{array}$ & $\begin{array}{l}87,50 \\
12,50\end{array}$ & $\begin{array}{c}20 \\
2\end{array}$ & $\begin{array}{c}90,91 \\
9,09\end{array}$ & $\begin{array}{c}41 \\
5\end{array}$ & 1,0000 \\
\hline $\begin{array}{l}\text { 9. Falta de estrutura na USF para a realização de visitas } \\
\text { domiciliares }\end{array}$ & $\begin{array}{l}\text { Sim } \\
\text { Não }\end{array}$ & $\begin{array}{c}19 \\
5\end{array}$ & $\begin{array}{l}79,17 \\
20,83\end{array}$ & $\begin{array}{l}18 \\
4\end{array}$ & $\begin{array}{l}83,44 \\
16,66\end{array}$ & $\begin{array}{c}37 \\
9\end{array}$ & 1,0000 \\
\hline 10. Falta de condições na USF para atendimento de urgência & $\begin{array}{l}\text { Sim } \\
\text { Não }\end{array}$ & $\begin{array}{c}20 \\
4\end{array}$ & $\begin{array}{l}83,34 \\
16,66\end{array}$ & $\begin{array}{c}21 \\
1\end{array}$ & $\begin{array}{c}95,46 \\
4,54\end{array}$ & $\begin{array}{c}41 \\
5\end{array}$ & 0,3488 \\
\hline 11. Falta de retaguarda de serviço de remoção & $\begin{array}{l}\text { Sim } \\
\text { Não }\end{array}$ & $\begin{array}{c}21 \\
3\end{array}$ & $\begin{array}{l}87,50 \\
12,50\end{array}$ & $\begin{array}{c}21 \\
1\end{array}$ & $\begin{array}{c}95,46 \\
4,54\end{array}$ & $\begin{array}{c}42 \\
4\end{array}$ & 0,6093 \\
\hline
\end{tabular}

informações da intimidade dos usuários e famílias, mas também ao projeto arquitetônico, às relações diárias e aos procedimentos e rotinas da unidade a da equipe. $\mathrm{Na}$ organização interna da rotina e dos fluxos da USF, a privacidade física e moral dos usuários e famílias devem ser preservadas, e constituir preocupação quando da estruturação dos serviços para que isso possa se ef etivar e serem situações evitadas.

Q uanto à falta de apoio estrutural para discutir e resolver os problemas éticos, Oberle e Hughes ${ }^{(24)}$, acreditam que existe a necessidade dos administradores de saúde reconhecerem o fardo carregado pelos enfermeiros e médicos como parte de sua prática profissional diária. Considerando que as decisões éticas são moduladas pelas condições do local de trabal ho, al guns autores ${ }^{(19,24)}$ recomendam que sejam implementadas estratégias para apoiar o processo de tomada de decisão e também sejam criadas oportunidades para os profissionais de saúde envolvidos na assistência se engajarem em discussões de temas éticos, devendo esta preocupação estar no foco central dos administradores que desejam fomentar um ambiente de trabal ho sadio e colaborativo.

Para uma organização realizar reflexões éticas é preciso desenvolver sua capacidade de comunicação, pois assim potencializa a capacidade dos trabalhadores para ponderar cursos de ação alternativos, justificar a escol ha feita com razões válidas, acrescentando que é esta capacidade de render contas que configura a responsabilidade (25).

Em relação falta de transparência da direção da USF na resolução de problemas com os profissionais, a gerência tem como um de seus grandes desafios pautar o enfrentamento dos conflitos pela essência das questões, e não pela personalidade dos envolvidos ou pelos interesses pessoais afetados, mostrando ao grupo que a resolução dos conflitos considera 0 mérito e não ataques e privilégios pessoais ${ }^{(25)}$.

$\mathrm{N}$ a tabela 6 , chama atenção a situação de excesso de famílias adscritas para cada equipe, que parece comum no cotidiano de trabalho dos enfermeiros e médicos participantes dessa pesquisa, já que todos apontaram sua ocorrência. 
Tabela 6 - Distribuição e associação da ocorrência dos problemas éticos nas relações com a organização e o sistema de saúde segundo categoria profissional. São Paulo, 2004-2005

\begin{tabular}{|c|c|c|c|c|c|c|c|}
\hline Problema & Freqüência & Enferm & $\left(n^{0}-\%\right)$ & Médic & $\left(n^{0}-\%\right)$ & Total & $\mathbf{p}$ \\
\hline $\begin{array}{l}\text { 1. Dificuldades para preservar privacidade por problemas } \\
\text { na estrutura física e rotinas da USF }\end{array}$ & $\begin{array}{c}\text { Já ocorreu } \\
\text { Nunca ocorreu }\end{array}$ & $\begin{array}{c}20 \\
3\end{array}$ & $\begin{array}{l}87,00 \\
13,00\end{array}$ & $\begin{array}{c}17 \\
5\end{array}$ & $\begin{array}{l}77,30 \\
22,70\end{array}$ & $\begin{array}{c}37 \\
8\end{array}$ & 0,3830 \\
\hline $\begin{array}{l}\text { 2. Falta de apoio estrtutural para discutir e resolver os } \\
\text { problemas éticos }\end{array}$ & $\begin{array}{c}\text { Já ocorreu } \\
\text { Nunca ocorreu }\end{array}$ & $\begin{array}{l}17 \\
4\end{array}$ & $\begin{array}{l}81,00 \\
19,00\end{array}$ & $\begin{array}{l}18 \\
4\end{array}$ & $\begin{array}{l}81,80 \\
18,20\end{array}$ & $\begin{array}{c}35 \\
8\end{array}$ & 0,9850 \\
\hline $\begin{array}{l}\text { 3. Falta de transparência da direção da USF na resolução } \\
\text { de problemas com profissionais }\end{array}$ & $\begin{array}{c}\text { Já ocorreu } \\
\text { Nunca ocorreu }\end{array}$ & $\begin{array}{c}15 \\
8\end{array}$ & $\begin{array}{l}65,20 \\
34,80\end{array}$ & $\begin{array}{c}12 \\
9\end{array}$ & $\begin{array}{l}57,10 \\
42,90\end{array}$ & $\begin{array}{l}37 \\
17\end{array}$ & 0,8560 \\
\hline 4. Excesso de familias adscritas para cada equipe & $\begin{array}{c}\text { Já ocorreu } \\
\text { Nunca ocorreu }\end{array}$ & $\begin{array}{c}13 \\
-\end{array}$ & $\begin{array}{c}100,00 \\
-\end{array}$ & $\begin{array}{l}14 \\
-\end{array}$ & $\begin{array}{c}100,00 \\
-\end{array}$ & $\begin{array}{c}27 \\
-\end{array}$ & 0,2280 \\
\hline 5. Restrição do acesso dos usuários aos serviços & $\begin{array}{l}\text { Já ocorreu } \\
\text { Nunca ocorreu }\end{array}$ & $\begin{array}{c}12 \\
6\end{array}$ & $\begin{array}{l}66,30 \\
33,30\end{array}$ & $\begin{array}{l}9 \\
11\end{array}$ & $\begin{array}{l}45,00 \\
55,00\end{array}$ & $\begin{array}{l}21 \\
17\end{array}$ & 0,3780 \\
\hline $\begin{array}{l}\text { 6. Demérito dos encaminhamentos feitos pelos médicos do } \\
\text { PSF }\end{array}$ & $\begin{array}{c}\text { Já ocorreu } \\
\text { Nunca ocorreu }\end{array}$ & $\begin{array}{l}17 \\
4\end{array}$ & $\begin{array}{l}81,00 \\
19,00\end{array}$ & $\begin{array}{c}19 \\
3\end{array}$ & $\begin{array}{l}86,40 \\
13,60\end{array}$ & $\begin{array}{c}36 \\
7\end{array}$ & 0,3560 \\
\hline 7. Dificuldades no acesso a exames complementares & $\begin{array}{c}\text { Já ocorreu } \\
\text { Nunca ocorreu }\end{array}$ & $\begin{array}{l}19 \\
-\end{array}$ & $\begin{array}{c}100,00 \\
-\end{array}$ & $\begin{array}{l}19 \\
-\end{array}$ & $\begin{array}{c}100,00 \\
-\end{array}$ & $\begin{array}{l}38 \\
-\end{array}$ & 1,0000 \\
\hline $\begin{array}{l}\text { 10. Dificuldades quanto ao retorno e confiabilidade dos } \\
\text { resultados de exames laboratoriais }\end{array}$ & $\begin{array}{c}\text { Já ocorreu } \\
\text { Nunca ocorreu }\end{array}$ & $\begin{array}{l}17 \\
4\end{array}$ & $\begin{array}{l}81,00 \\
19,00\end{array}$ & $\begin{array}{c}19 \\
1\end{array}$ & $\begin{array}{c}95,00 \\
5,00\end{array}$ & $\begin{array}{c}36 \\
5\end{array}$ & 0,2120 \\
\hline $\begin{array}{l}\text { 11. Falta de estrutura na USF para a realização de visitas } \\
\text { domiciliares }\end{array}$ & $\begin{array}{c}\text { Já ocorreu } \\
\text { Nunca ocorreu }\end{array}$ & $\begin{array}{l}17 \\
2\end{array}$ & $\begin{array}{l}89,50 \\
10,50\end{array}$ & $\begin{array}{c}15 \\
3\end{array}$ & $\begin{array}{l}83,30 \\
16,70\end{array}$ & $\begin{array}{c}32 \\
5\end{array}$ & 0,7130 \\
\hline $\begin{array}{l}\text { 12. Falta de condições na USF para atendimento de } \\
\text { urgência }\end{array}$ & $\begin{array}{c}\text { Já ocorreu } \\
\text { Nunca ocorreu }\end{array}$ & $\begin{array}{l}19 \\
-\end{array}$ & $\begin{array}{c}100,00 \\
-\end{array}$ & 21 & $\begin{array}{c}100,00 \\
-\end{array}$ & $\begin{array}{l}40 \\
-\end{array}$ & 0,0860 \\
\hline 13. Falta de retaguarda de serviço de remoção & $\begin{array}{c}\text { Já ocorreu } \\
\text { Nunca ocorreu }\end{array}$ & $\begin{array}{l}21 \\
-\end{array}$ & $\begin{array}{c}100,00 \\
-\end{array}$ & $\begin{array}{l}21 \\
-\end{array}$ & $\begin{array}{c}100,00 \\
-\end{array}$ & $\begin{array}{l}42 \\
-\end{array}$ & 0,7580 \\
\hline
\end{tabular}

Outros problemas éticos bastante vividos pelos sujeitos do estudo forma a dificuldade no acesso a exames complementares; a falta de condições da USF para atendimentos de urgência e falta de retaguarda de serviço de remoção.

Vale lembrar que, embora na organização e planejamento das unidades básicas de saúde não se preveja 0 atendimento de urgências, muitas vezes, a USF éo único recurso de saúde ao qual a população tem acesso. A ssim, parece que a rede tem de rediscutir os limites e a resol ubilidade de cada serviço, pois são estes que devem se adequar para atender as necessidades de saúde da população e não o contrário.

\section{CONSIDERAÇÕESFINAIS}

Os resultados desta pesquisa confirmam o que os poucos estudos sobre bioética real izados na atenção básica apontam: que os problemas éticos neste nível da atenção são situações típicas do cotidiano e não as situações dilemáticas, mais típicas do contexto hospitalar especializado. Entretanto, isto não significa que sejam menos importantes, mas reforçam que as características dos problemas são relacionadas com o cenário em que a assistência ocorre.

0 fato de serem problemas comuns a situações cotidianas os torna sutis, a ponto de passarem despercebidos, o que faz com que seja mais difícil conseguir mudanças de atitudes das equipes para formar o vínculo necessário no PSF.

Os resultados das medidas de associação utilizadas, embora este seja um estudo de caráter exploratório, apontam não haver correlação entre a categoria profissional e a percepção de problemas éticos.

Chama atenção o fato de al gumas das situações listadas não serem consideradas problemas éticos pelos sujeitos do presente estudo, pois o instrumento de coleta de dados foi construído a partir do apontado pelos próprios enfermeiros e médicos em estudo anterior e não com base em literatura ou opinião dos expertos em bioética ou ética. Entretanto, esta é uma possibilidade plausível dado o pluralismo moral das sociedades atuais, pois os valores e princípios aceitos pelos profissionais acabam por determinar seuma dada situação será tida ou não como problema ético. 


\section{REFERÊNCIAS}

1. B rody H. Transparency: informed consent in primary care. Hasting Centers Report. 1989; sep/oct: 5-9.

2. Gracia D. Bioética clínica. Santa Fé de B ogotá: El Buho; 1998.

3. Fetters M D, B rody H. The epidemiology of bioethics. J Clin Ethics 1999; 10: 107-15

4. Mayer-Braunack $A J$. What makes a problem an ethical problem? A $n$ empirical perspective on the nature of ethical problems in general practice. J Med Ethics 2001; 27: 98-103.

5. Zoboli ELCP. B ioética e atenção básica: um estudo de ética descritiva com enfermeiros e médicos do Programa Saúde da Família. [tese]. São Paulo (SP): Faculdade de Saúde Pública da Universidade de São Paulo; 2003.

6. Sugarman J, organizador. Ethics in primary care. New York: McGraaw-Hill; 2000; p. xiii-xvi.

7. Maliandi R. Ética: conceptos y problemas. Buenos A ires: Biblos; 1991.

8. B eauchamp TL, Childress JF. Principles of biomedical ethics. 5. ed. New Y ork: Oxford University Press; 2001.

9. Sulmasy DP, Sugarman J. The many methods of medical ethics. In: Sugarman J, Sulmasy DP, organizadores. M ethods in medical ethics. Washington DC: Georgetown University Press; 2001. p. 3-18.

10. Sánchez-González M . La investigación bioética: tipos, funciones y relaciones mutuas. Cuadernos del Programa Regional de Bioética 1998; 6: 57-76.

11. Robillard HM, High DM, Sebastian JG, Pisaneschi JI, Perritt LJ, Mahler DM. Ethical issues in primary health care: a survey of practioners' perceptions. Journal of Community Health 1989; 14: 9-17.

12. Wagner $\mathrm{N}$, Ronen I. Ethical dilemmas experienced by hospital and community nurses: an Israeli survey. Nurs Ethics. 1996; 3: 294304.

13. M orrow E. A ttitudes of women from vulnerable populations toward physician-assisted death: a qualitative approach.J Clin Ethics 1997; 8: 279-89.

14. M atumoto S. 0 acolhimento: um estudo sobre seus componentes e sua produção em uma unidade da rede básica de serviços de saúde. [dissertação]. Ribeirão Preto (SP): Escola de Enfermagem de Ribeirão Preto da Universidade de São Paulo; 1998.

15. M atumoto S, M ishima SM , Pinto IC. Saúde Coletiva: um desafio para a enfermagem. Cad. Saúde Públ 2001 17: 233-41.

16. Silva A, Dal maso A SW. A gente comunitário de saúde: 0 ser, 0 saber, o fazer. Rio de Janeiro: Fiocruz; 2002.

17. Craco PF. A ção comunicativa no cuidado à saúde da família: encontros e desencontros entre profissionais de saúde e usuários. [tese]. Ribeirão Preto (SP): Escola de Enfermagem de Ribeirão Preto da Universidade de São Paulo; 2006.

18. Chiesa AM, Veríssimo M L OR. A educação em saúde na prática do PSF. In: Instituto para o Desenvolvimento da Saúde, U niversidade deSão Paulo, M inistério da Saúde. M anual deEnfermagem. B rasília:
M inistério da Saúde; 2001. p. 34-42.

19. Pontes RA, Lacerda MR, Torzetto V. Questões ético-legais vivenciadas pelos profissionais de um serviço municipal de saúde indagações e proposições. Cogitare Enferm. 2001; 6(2): 36-42.

20. Fortes PAC. Ética e saúde. São Paulo: EPU; 1998.

21. Germano RM . A ética e o ensino de ética na enfermagem do B rasil. São Paulo: Cortez; 1993.

22. Thomas J, Wainwright P. Community nurses and health promotion: ethical and political perspectives. Nurs Ethics 1996; 3:97-107.

23. Makadon HJ, Gibbons M P. Nurses and physicians: prospects for collaboration. Ann Intern Med 1985; 103:134-6.

24. Oberle K, Hughes D. Doctors' and nurses' perceptions of ethical problems in end-of-life decisions. J A dv Nurs 2001; 33: 707-15.

25. Zoboli ELCP. Ética e administração hospitalar. São Paulo: Loyola/ Editora do Centro Universitário São Camilo; 2002.

Cogitare Enferm 2006 mai/ago; 11(2):133-42 